\title{
A patient with chronic myeloid leukemia and situs inversus totalis: A case report
}

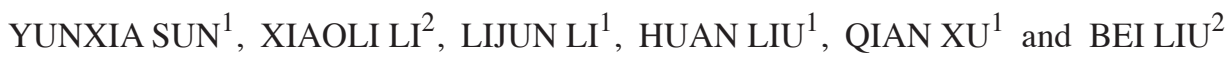 \\ ${ }^{1}$ Medical Department, The First Clinical Medical College; ${ }^{2}$ Department of Hematology, \\ The First Affiliated Hospital, Lanzhou University, Lanzhou, Gansu 730000, P.R. China
}

Received June 26, 2016; Accepted July 7, 2017

DOI: $10.3892 / \mathrm{ol} .2017 .7166$

\begin{abstract}
In the present study, a case of chronic myeloid leukemia (CML) with complete situs inversus in a 68-year-old female patient was reported. The patient presented with general weakness, abdominal distension and tenderness in the right hypochondrium. A chest X-ray revealed a right-sided heart. Ultrasonography revealed situs inversus totalis. A bone marrow smear demonstrated CML in the accelerated phase. Imatinib mesylate was subsequently administered; the patient stopped taking imatinib mesylate following discharge from the hospital. The patient presented with dizziness, fatigue, and abdominal distention and pain 1 year subsequently. A bone marrow smear demonstrated CML in the blast crisis phase; CML had progressed to acute myeloid leukemia (AML) M2a. The patient was treated with imatinib mesylate and cytarabine. After 5 days, the white blood cell count had decreased compared with that measured at the time of admission, and the previous relevant symptoms had disappeared. The patient succumbed to AML 3 months after discharge from the hospital. Situs inversus totalis is an uncommon congenital anomaly that often occurs concomitantly with other disorders. The present study documented, to the best of our knowledge, the second recorded case of CML in a patient with situs inversus totalis. Previous studies on the pathogenesis of situs inversus have suggested it is caused by embryonic cells failing to rotate normally during early embryonic development. Although there are case reports of situs inversus totalis in patients with cancer, there are few reports on the association between situs inversus totalis and cancer. The present study examined a case of CML with situs inversus totalis and assessed whether the latter may be associated with cancer.
\end{abstract}

Correspondence to: Dr Bei Liu, Department of Hematology, The First Affiliated Hospital, Lanzhou University, 1 Donggangxilu Street, Lanzhou, Gansu 730000, P.R. China

E-mail: liubeiff@163.com

Key words: chronic myeloid leukemia, situs inversus totalis, kinesin 3

\section{Introduction}

Situs inversus is a rare congenital anomaly that occurred in $1 / 8,000-1 / 25,000$ people globally in 2001 (1). Situs inversus totalis (SIT) is an uncommon congenital anomaly that often occurs concomitantly with other disorders $(1,2)$, including congenital heart disease, ciliary dyskinesia, Kartagener's syndrome and polysplenia (3-5). Chronic myeloid leukemia (CML) is a malignant clonal disorder of pluripotent hematopoietic stem cells and accounts for $15 \%$ of all adult leukemia cases in the United States in 2007 (6). The diagnosis of CML is performed on the basis of detecting the breakpoint cluster region protein (BCR)-Abelson murine leukemia viral oncogene homolog 1 (ABL) gene or Philadelphia chromosome $[\mathrm{t}(9 ; 22)(\mathrm{q} 34 ; \mathrm{q} 11.2)](7)$. The translocation is detected using routine cytogenetics, fluorescence in situ hybridization (FISH) and molecular reverse-transcription polymerase chain reaction tests (7). The global CML annual incidence rate was 1.6-2.0/100,000 people per year (8). The CML annual incidence rate in China was 0.36/10 million people in 1992, which was decreased compared with that in Western countries (9). The first generation of tyrosine inhibitor imatinib as a first-line treatment of patients with CML is associated with a 10 -year survival rate of $85-90 \%$ (10). To the best of our knowledge, the literature reports only 1 case of CML in a patient exhibiting SIT; the patient was a 69 -year-old male exhibiting chronic granulocytic leukemia and SIT, which had induced a right-sided splenomegaly that was originally diagnosed as a hepatomegaly (11). The present study reported a case of CML with complete situs inversus in a 68-year-old female patient. A series of imaging studies revealed total mirror reversal of the thoracic and abdominal organs. A bone marrow smear supported the diagnosis of CML in the accelerated phase. The co-occurrence of CML and SIT prompted the present study to evaluate whether these conditions may be associated.

\section{Case report}

A 68-year-old female patient was admitted to the Department of Hematology at The First Affiliated Hospital of Lanzhou University (Lanzhou, China) on September 3, 2012. The patient reported a 2 -month history of general weakness and night sweats and a 1-month history of experiencing 
Table I. Types of malignancy in patients with SI or SA.

\begin{tabular}{lcc}
\hline Type of cancer & No. of cases & SI/SA \\
\hline Gastric cancer & 15 & $14 / 1$ \\
Colorectal adenocarcinoma & 11 & $11 / 0$ \\
Lung cancer & 10 & $10 / 0$ \\
Renal cell carcinoma & 9 & $6 / 3$ \\
Esophageal & 7 & $7 / 0$ \\
(squamous or adenocarcinoma) & & \\
Bile duct cancer & 5 & $3 / 2$ \\
Lymphoma & 5 & $5 / 0$ \\
Hepatocellular carcinoma & 4 & $4 / 0$ \\
Pancreatic adenocarcinoma & 4 & $3 / 1$ \\
Endometrial cancer & 2 & $2 / 0$ \\
Chronic granulocytic leukemia & $2^{\mathrm{a}}$ & $2 / 0$ \\
Periampullary carcinoma & 2 & $1 / 1$ \\
Appendiceal mucinous & 1 & $1 / 0$ \\
adenocarcinoma & & \\
Adrenal tumor & 1 & $1 / 0$ \\
Bladder cancer & 1 & $1 / 0$ \\
\hline
\end{tabular}

ancludes the case reported in the present study. SI, situs inversus; SA, situs ambiguous.

abdominaldistensionandtendernessintherighthypochondrium. A chest X-ray and conventional electrocardiogram revealed a right-sided heart. Abdominal ultrasound revealed SIT, a condition characterized by total mirrored reversal of the thoracic and abdominal organs.

A conventional electrocardiogram revealed dextrocardia (Fig. 1). A chest X-ray revealed heart and stomach gas on the right side (Fig. 2). An abdominal ultrasound examination indicated SIT and spleen enlargement. A complete blood count test obtained the following results: $12 \%$ original and naive cells (normal range, 0\%); hemoglobin, $109 \mathrm{~g} / 1$ (normal range, $110-150 \mathrm{~g} / \mathrm{l}) ; 1.897 \times 10^{10}$ leukocytes/1 (normal range, $0.400-1.000 \times 10^{10}$ leukocytes/1); $1.176 \times 10^{10}$ neutrophils/1 (normal range, $0.200-0.700 \times 10^{10}$ neutrophils/l); $2.85 \times 10^{9}$ lymphocytes $/ 1$ (normal range, $1.50-4.00 \times 10^{9}$ lymphocytes $/ 1$ ); $1.52 \times 10^{9}$ monocytes $/ 1$ (normal range, $0.00-0.45 \times 10^{9}$ monocytes $/ 1$ ); $3.8 \times 10^{8}$ eosinophils/l (normal range, $0.5-3.0 \times 10^{8}$ eosinophils $\left./ 1\right) ; 2.47 \times 10^{9}$ basophils $/ 1$ (normal range, $0.00-0.20 \times 10^{9}$ basophils/l) and $3.86 \times 10^{11}$ platelets/l (normal range, $1.00-3.00 \times 10^{11}$ platelets/l). A bone marrow smear demonstrated a myeloid:erythroid ratio of 3.68:1 (normal range, 2.00-4.00:1), with original granular cells accounting for $18.0 \%$ of the total cells (normal range, 0.5-2.0\%), and supported the diagnosis of CML in the accelerated phase. Karyotype analysis demonstrated 46, XX, t $(9 ; 22 ; \mathrm{q} 34 ; \mathrm{q} 11.2)$ in the 20 assessed cells and was the sole abnormality observed. FISH was performed using the gene locus-specific probe (GLP) BCR/GLP ABL1 to identify the BCR-ABL1 fusion gene. The rate of BCR-ABL1 fusion was $84 \%$, as determined using FISH (Fig. 3). The present study extracted the bone marrow samples from the patients and sent the BCR-ABL1 fusion gene to undergo a quantitative

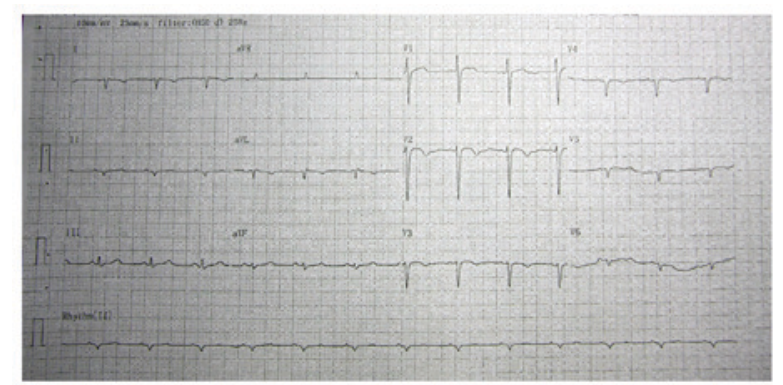

Figure 1. Electrocardiogram of the patient revealed sinus rhythm and dextrocardia. I, lead I; II, lead II; III, lead III.

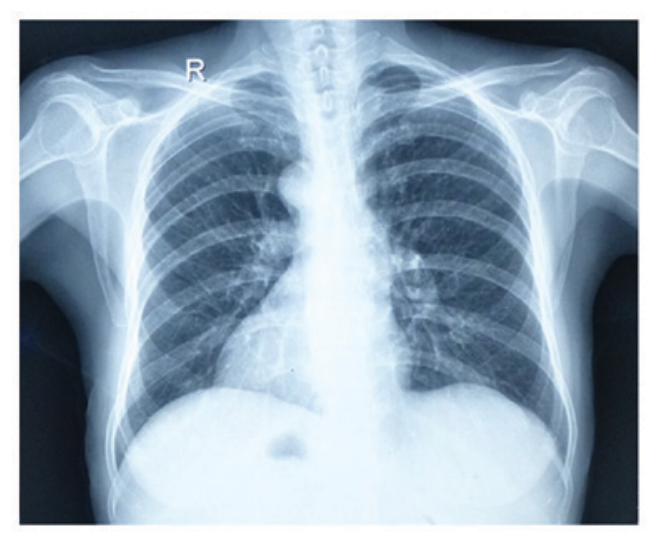

Figure 2. Chest X-ray of the patient. The heart is visible on the left side and stomach gas is visible on the right side. $\mathrm{R}$, right side.

polymerase chain reaction. The method was determined using fluorescence quantitative polymerase chain reaction. This method is from the bone marrow mononuclear cells in the separation and purification of RNA, TRIzol (TransStart Inc., Beijing, China) reagent was used to extract total RNA. Subsequently, reverse transcription of cDNA was performed using the reverse transcription kit (Takara Bio Inc., Otsu, Japan), using RNA as a template. The temperature protocol were as follows: $37^{\circ} \mathrm{C}$ for $15 \mathrm{~min}, 85^{\circ} \mathrm{C}$ for $5 \mathrm{sec}$ and kept at $4^{\circ} \mathrm{C}$ until use. The fluorophore used for the polymerase chain reaction was Dalian's Tap enzyme (Takara Bio Inc.). The target gene primers were as follows: BCR-ABL, bcr: 5'-AGG GTGCACAGCCGCAACGGC-3' and abl, 5'-GGCTTCACT CAGACCCTGAGG-3. The reference gene was $\beta$-actin. The reference gene primers were as follows: $\beta$-actin, forward: 5'-GGAGATTACTGCCCTGGCTCCTA-3' and reverse: 5'-GACTCATCGTACTCCTGCTTGCTG-3'. The thermocycling conditions were as follows: $95^{\circ} \mathrm{C}$ for $30 \mathrm{sec}$ for 1 cycle, $95^{\circ} \mathrm{C}$ for $5 \mathrm{sec}$ and $60^{\circ} \mathrm{C}$ for $20 \mathrm{sec}$ for 40 cycles. The results were expressed as $2^{-\Delta \Delta C q}(12)$. The quantity of BCR-ABL transcript was normalized to the ABL expression level. The copy number of BCR-ABL fusion gene and the copy number of ABL were calculated, and the result was expressed as the ratio of BCR-ABL copy number to ABL copy number. The present patient's BCR-ABL1 fusion gene quantitative detection revealed a BCR-ABL1 fusion gene-positive, a BCR-ABL1 copy number of $4.96 \times 10^{4}$, and a BCR-ABL1/ABL1 ratio of $5: 18$. Imatinib mesylate $(600 \mathrm{mg} / \mathrm{day})$ was subsequently administered from September 12, 2012 until the patient 


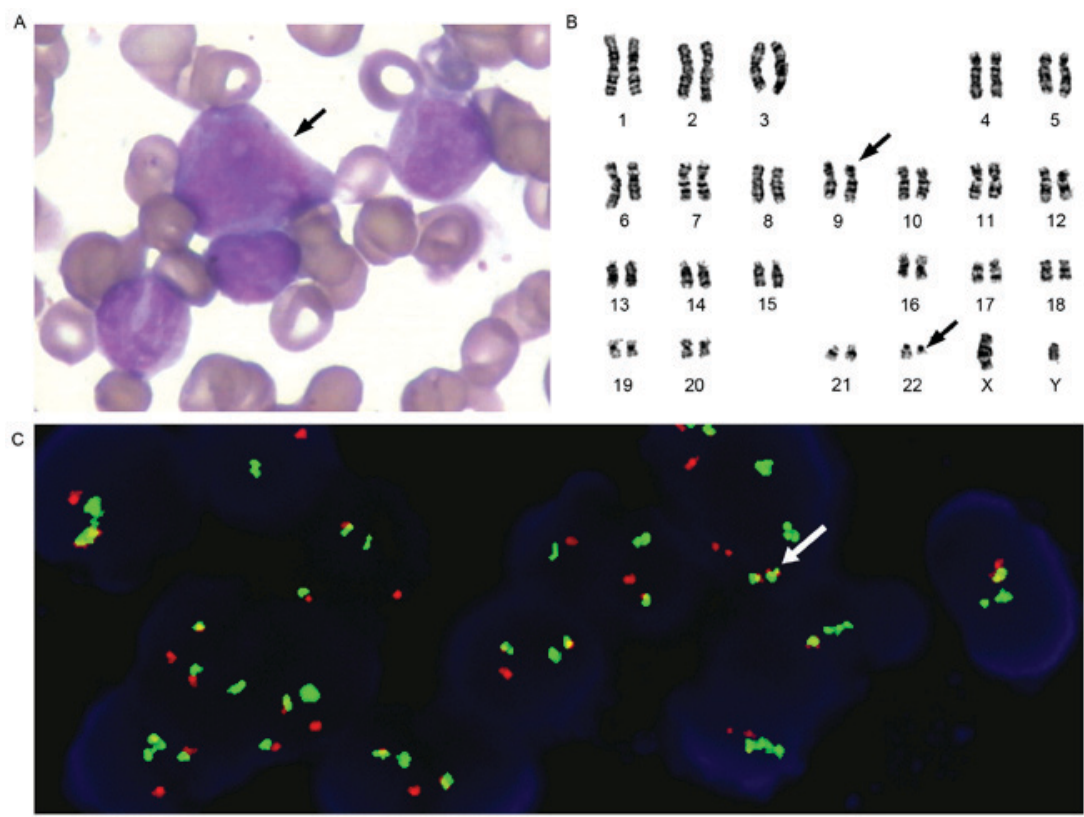

Figure 3. Results of bone marrow smear, karyotype and FISH analysis of the patient prior to treatment. (A) The bone marrow smear revealed a myeloproliferative disorder with hyperactivity in the medullary system; the myeloblast accounted for $18 \%$ of the total blood cells. (B) Karyotype analysis revealed 46 , XY, $\mathrm{t}(9 ; 22 ; \mathrm{q} 34 ; \mathrm{q} 11.2)$ in the 20 assessed cells, which was the sole abnormality observed; the $\mathrm{t}(9 ; 22)$ is indicated by arrows. (C) FISH was performed using a GLP BCR/GLP ABL1 to identify BCR-ABL1 fusion genes; $84 \%$ of the cells revealed 1 yellow, 2 red and 1 green signals and these were BCR-ABL1 ${ }^{+}$cells. FISH, fluorescent in situ hybridization; GLP, gene locus-specific probe; ABL, ABL proto-oncogene; FISH, fluorescent in situ hybridization.

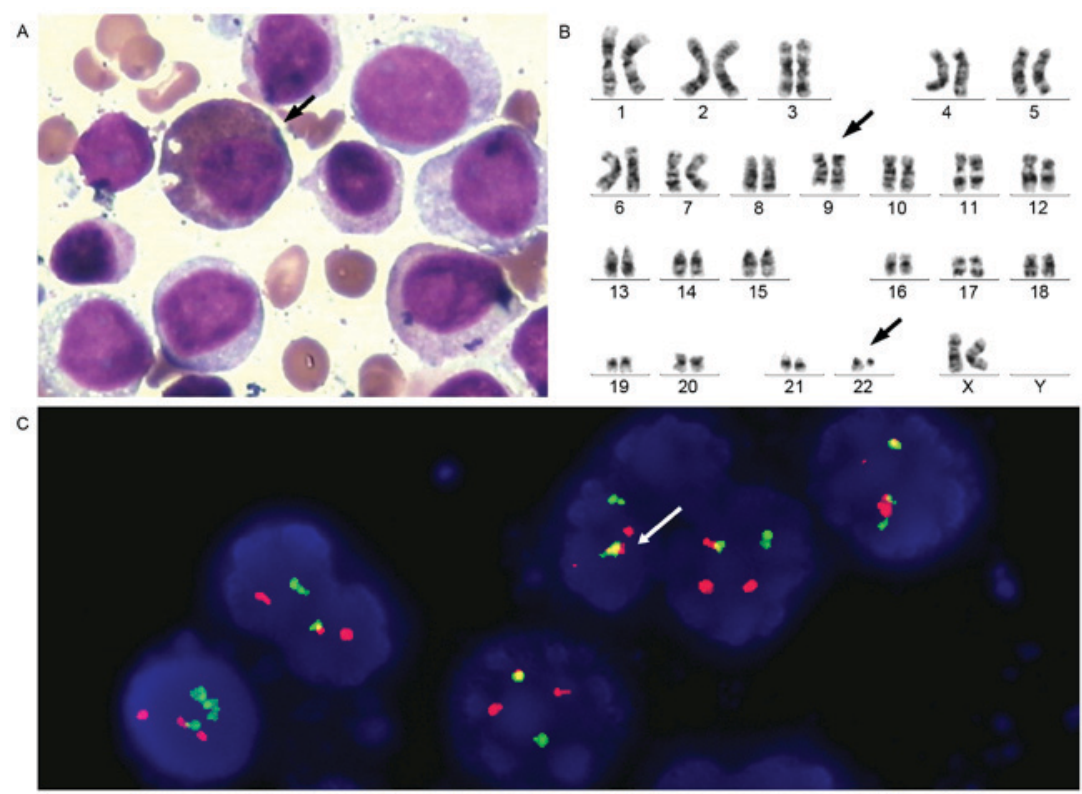

Figure 4. Results of bone marrow smear, karyotype and FISH analysis of the patient following treatment. (A) The bone marrow smear revealed a myeloproliferative disorder with hyperactivity in the medullary system; the myeloblast accounted for $21 \%$ of the total blood cells, indicating chronic myeloid leukemia in the blast crisis (convert acute myeloid leukemia M2a). (B) Karyotype analysis revealed 46, XY,t(9;22;q34;q11.2) in the 20 assessed cells, which was the sole abnormality observed; the $\mathrm{t}(9 ; 22)$ is indicated by arrows. (C) FISH was performed using a GLP BCR/GLP ABL1 to identify BCR-ABL1 fusion genes; $90 \%$ of the cells revealed 1 yellow, 2 red and 1 green signal and these were BCR-ABL1 ${ }^{+}$cells. FISH, fluorescent in situ hybridization; GLP, gene locus-specific probe; ABL, ABL proto-oncogene.

ceased taking imatinib mesylate following discharge from the hospital on September 16, 2012.

The patient last presented on November 20, 2013 with dizziness, fatigue, and abdominal distention and pain. A bone marrow smear demonstrated a myeloid:erythroid ratio of 57.33:1.00, with original granular cells accounting for $21 \%$ of the total cells, and supported the diagnosis of CML in the blast crisis phase; CML had progressed to acute myeloid leukemia (AML) M2a. Karyotype analysis also revealed 46, XX, $t(9 ; 22 ; q 34 ; q 11.2)$ in the 20 assessed cells. The positive rate of BCR-ABL1 fusion was 90\%, as determined by FISH (Fig. 4).

The initial white blood cell (WBC) count was $2.495 \times 10^{10} / 1$ (normal range, $4-10 \times 10^{10} / 1$ ). After 3 days of treatment with imatinib mesylate $(600 \mathrm{mg} /$ day) the WBC count of the patient 
Table II. Patients with multiple types of primary malignancy and SI or SA.

\begin{tabular}{lcc}
\hline Type of cancer & SI/SA & (Refs.) \\
\hline Combined hepatocellular and cholangiocellular carcinoma & $1 / 0$ & $(24)$ \\
Synchronous colonic tumors on the proximal transverse and sigmoid colon & $1 / 0$ & $1 / 0$ \\
Metachronous rectosigmoid colon and gastric cancer & $1 / 0$ \\
Lung cancer and mediastinal tumor & $1 / 0$ & $1 / 0$ \\
Synchronous double cancer originating from the stomach and rectum & $1 / 0$ & $(25)$ \\
Synchronous early cancer of the esophagus and larynx & $1 / 0$ \\
Laryngeal neoplasms & $0 / 1$ \\
Hepatocellular and early signet ring cell gastric carcinoma & $0 / 1$ \\
Double cancer of the stomach and esophagus & $0 / 1$ & $(26)$ \\
Gastrointestinal neoplasms, bladder and mammary cancer, and basal cell carcinoma & $(30)$ \\
Carcinoma of the right breast, bladder cancer, endometrial adenocarcinoma and & $(16)$ \\
non-Hodgkin lymphoma of the scalp & $(32)$
\end{tabular}

SI, situs inversus; SA, situs ambiguous.

Table III. Patients with lymphoma or leukemia and SI or SA.

\begin{tabular}{|c|c|c|c|c|}
\hline Type of cancer & Age & Sex & $\mathrm{SI} / \mathrm{SA}$ & (Refs.) \\
\hline Hairy cell leukemia & 73 & Male & $1 / 0$ & $(33)$ \\
\hline Mantle cell lymphoma & 73 & Male & $1 / 0$ & $(34)$ \\
\hline Malignant lymphoma of the stomach & 51 & Female & $1 / 0$ & $(2)$ \\
\hline Splenic lymphomatous infiltration & 65 & Male & $1 / 0$ & $(35)$ \\
\hline Ileocecal lymphoma & 4 & Male & $1 / 0$ & $(36)$ \\
\hline Chronic granulocytic leukemia & 69 & Male & $1 / 0$ & $(11)$ \\
\hline Chronic granulocytic leukemia ${ }^{a}$ & 68 & Female & $1 / 0$ & \\
\hline
\end{tabular}

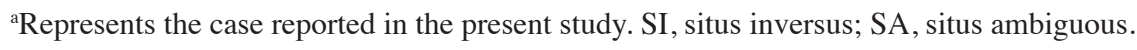

had increased to $5.083 \times 10^{10} / 1$, at which point the imatinib mesylate treatment was replaced by the continuous intravenous infusion of cytarabine $\left(200 \mathrm{mg} / \mathrm{m}^{2}\right.$ day). After 2 days of cytarabine treatment, the WBC count had decreased to $1.7 \times 10^{10} / 1$ and the previous relevant symptoms were no longer present. The patient was discharged from the hospital on November 28, 2013 and succumbed to AML 3 months subsequently. The patient's family provided written informed consent for the present study to be published.

\section{Discussion}

The anatomical arrangement of human organs may be described using the following categories: Situs solitus; situs inversus; and situs ambiguous. The normal position of the thoracic and abdominal viscera is referred to as situs solitus. Situs inversus is a rare congenital anomaly and is classified as either SIT or partial situs inversus (13). SIT is associated with an exchange in the position of the thoracic and abdominal viscera between the left and right sides, resulting in a mirror reversal of the thoracic and abdominal organs (14). Situs ambiguous is an uncommon condition in which the cardiac

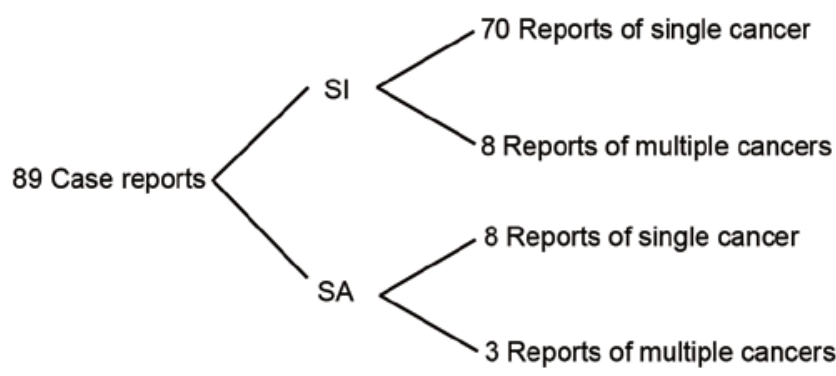

Figure 5. Distribution of reported cases of cancer in patients with SI or SA. SI, situs inversus; SA, situs ambiguous.

and visceral organs are abnormally distributed without mirror imaging from conventional anatomy (15).

Situs inversus is not a premalignant condition. However, rare synchronous and primary malignancies have been reported in the literature; the PubMed database includes 89 case reports of patients with cancer exhibiting situs inversus or situs ambiguous between 1952 and 2015 (Fig. 5). Among these were 78 and 11 cases of cancer in patients exhibiting situs inversus and situs ambiguous, respectively, 
and only 1 case of CML in a patient exhibiting SIT (11). Among these 89 case reports in the Pubmed database, the four most common cancers reported in patients with situs inversus included gastric cancer, colorectal adenocarcinoma, lung cancer and renal cell carcinoma (Table I). Information on multiple primary malignancies in patients with situs inversus or situs ambiguous (Table II), and cases of lymphoma and chronic granulocytic leukemia with situs inversus or situs ambiguous was provided (Table III).

Although the occurrence of malignancy in patients with SIT may be coincidental, certain studies have suggested a possible association between malignancy and SIT (16-18). Previous studies have proposed that unidentified genes affecting the left-right axis arrangement may be associated with cancer susceptibility $(19,20)$. Although this may potentially explain the occurrence of cancer in the patient with SIT assessed in the present study, no genes have been conclusively identified as candidates for this dual role to the best of our knowledge (16). The pathogenetic mechanisms underlying SIT were elucidated by previous studies, and it was shown that kinesin (KIF)3, an intracellular motor protein, has an important role in establishing left-right asymmetry (17). Nodal flow is autonomously generated by the rotation of cilia tilted toward the posterior of the cells of the ventral node. KIF3 molecular motors assist in the development of these cilia but are dysfunctional in $\operatorname{SIT}(21,22)$. It has also been reported that the KIF3 complex is involved in neural $(\mathrm{N})$-cadherin transport to the cell surface. The cell adhesion molecules $\mathrm{N}$-cadherin and $\beta$-catenin are not transported to the cell surface in patients with SIT due to the absence of function in the KIF3 complex (18). Consequently, the excess $\beta$-catenins in the cytoplasm enter the nucleus and activate genes associated with cell proliferation, thereby facilitating the development and progression of cancer in patients with SIT (17). Cell-cell adhesion assists in coordinating cellular organization and collective cell migration, and is critical for the directional looping of developing embryonic organs (23). A previous study assessed the influence of collective cell migration on the breaking of left-right symmetry, and established a 2D microscale system that may be useful for fetal drug screening to assist in identifying and potentially inhibiting birth defects associated with alterations in cell-cell adhesion (24).

Since the data in the literature indicated that the incidence of situs inversus with overall malignancy or leukemia is extremely low, the present study concluded that the occurrence of CML with SIT in the patient assessed in the present study may be by chance. However, the diagnosis of SIT may also be established by future, larger studies, which could provide a means of predicting the disease and methods to prevent its progression.

\section{References}

1. Aylsworth AS: Clinical aspects of defects in the determination of laterality. Am J Med Genet 101: 345-355, 2001.

2. Murakami S, Terakado M, Misumi M, Tsuji Y, Okubo K, Hirayama R, Inoue K and Arai E: Situs inversus totalis with malignant lymphoma of the stomach: Report of a case. Surg Today 33: 533-536, 2003.

3. Schmutzer KJ and Linde LM: Situs inversus totalis associated with complex cardiovascular anomalies. Am Heart J 56: 761-768, 1958.
4. Katsuhara K, Kawamoto S, Wakabayashi T and Belsky JL: Situs inversus totalis and Kartagener's syndrome in a Japanese population. Chest 61: 56-61, 1972.

5. Park SS, Min BW, Kim WB, Han HJ, Yong HS, Kim SJ, Kim CS and Mok YJ: Double cancer of the stomach and oesophagus with situs ambiguus with polysplenia: The importance of preoperative evaluation. Dig Liver Dis 37: 799-802, 2005.

6. National Comprehensive Cancer Network: NCCN clinical practice guideline in oncology: Chronic myelogenous leukemia, V.2.2008. NCCN Web Site. 8-28-2007. https://www.nccn.org/professionals/ physician_gls/f_guidelines.asp\#cll. Accessed July 26, 2017.

7. Bennett JM, Dsouza KG, Patel M and O'Dwyer K: 'Preleukemic or smoldering' chronic myelogenous leukemia (CML):BCR-ABL1 positive: A brief case report. Leukemia Res Rep 4: 12-14, 2014.

8. Druker BJ and Lee SJ: Chapter 43: Chronic leukemias: Section 1: Chronic myelogenous leukemia. DeVita, Vincent T.; Lawrence, Theodore S.; Rosenberg, Steven A (eds.) In: Devita, Hellman \& Rosenberg's Cancer: Principles and Practice of Oncology. Wolters Kluwer - Lippincott Williams \& Wilkins, Philadelphia, PA, USA. 8th Edition, pp2268-2277, 2008

9. Yang CL and Zhang XB: An epidemiological ivvestigation of leukemia and aplastic anemia. Investigation on incidence of leukemia in China. J China Acad Med Sci 14: 12-18, 1992.

10. Kalmanti L, Saussele S, Lauseker M, Müller MC, Dietz CT, Heinrich L, Hanfstein B, Proetel U, Fabarius A, Krause SW, et al: Safety and efficacy of imatinib in CML over a period of 10 years: Data from the randomized CML-study IV. Leukemia 29: 1123-1132, 2015.

11. Kasili EG and Gaya Z: A case of chronic granulocytic leukemia with a right sided splenomegaly: Case-report. East Afr Med J 65: $140-143,1988$.

12. Livak KJ and Schmittgen TD: Analysis of relative gene expression data using real-time quantitative PCR and the 2(-Delta Delta C(T)) method. Methods 25: 402-408, 2001.

13. Kim YW, Ryu H, Kim DS and Kim IY: Double primary malignancies associated with colon cancer in patients with situs inversus totalis: Two case reports. World J Surg Oncol 9: 109, 2011.

14. Varano NR and Merklin RJ: Situs inversus: Review of the literature, report of four cases and analysis of the clinical implications. J Int Coll Surg 33: 131-148, 1960.

15. RS C, V K and SL R: Robbins Pathologic Basis of Disease. 4th edition. Asia-Pac J Clin onco, 777: 1989.

16. Galiatsatos P, Kasprzak L, Chong G, Jass JR and Foulkes WD: Multiple primary malignancies in a patient with situs ambiguus. Clin Genet 69: 528-531, 2006.

17. Haruki T, Maeta Y, Nakamura S, Sawata T, Shimizu T, Kishi K, Miyasaka S, Maeta H, Morimoto K and Taniguchi I: Advanced cancer with situs inversus totalis associated with KIF3 complex deficiency: Report of two case. Surg Today 40: 162-166, 2010.

18. Teng J, Rai T, Tanaka Y, Takei Y, Nakata T, Hirasawa M, Kulkarni AB and Hirokawa N: The KIF3 motor transports $\mathrm{N}$-cadherin and organizes the developing neuroepithelium. Nat Cell Biol 7: 474-482, 2005.

19. Worley KE, Shieh D and Wan LQ: Inhibition of cell-cell adhesion impairs directional epithelial migration on micropatterned surfaces. Integr Biol (Camb) 7: 580-590, 2015

20. Bamford RN, Roessler E, Burdine RD, Saplakoğlu U, dela Cruz J, Splitt M, Goodship JA, Towbin J, Bowers P, Ferrero GB, et al: Loss-of-function mutations in the EGF-CFC gene $\mathrm{CFCl}$ are associated with human left-right laterality defects. Nat Genet 26: 365-369, 2000.

21. Peeters H, Debeer P, Bairoch A, Wilquet V, Huysmans C, Parthoens E, Fryns JP, Gewillig M, Nakamura Y, Niikawa N, et al: PA26 is a candidate gene for heterotaxia in humans: Identification of a novel PA26-related gene family in human and mouse. Hum Genet 112: 573-580, 2003.

22. Hirokawa N: Determination of left-right asymmetry: Role of cilia and KIF3 motor proteins. News Physiol Sci 15: 56, 2000.

23. Hirokawa N, Tanaka Y, Okada Y and Takeda S: Nodal flow and the generation of left-right asymmetry. Cell 125: 33-45, 2006.

24. Teng J, Rai T, Tanaka Y, Takei Y, Nakata T, Hirasawa M, Kulkarni AB and Hirokawa N: The KIF3 motor transports $\mathrm{N}$-cadherin and organizes the developing neuroepithelium. Nat Cell Biol 7: 474-482, 2005.

25. Worley KE, Shieh D and Wan LQ: Inhibition of cell-cell adhesion impairs directional epithelial migration on micropatterned surfaces. Integr Biol (Camb) 7: 580-590, 2015.

26. Kamiike W, Itakura T, Tanaka H, Hatanaka N, Nakamuro M, Miyata M and Izumi H: Hepatic segmentectomy on primary liver cancer with situs inversus totalis. HPB Surg 9: 169-173, 1996. 
27. Horie M, Arai H, Noguchi S, Suzuki M, Sakamoto Y and Oka T: Kartagener syndrome with lung cancer and mediastinal tumor Nihon Kokyuki Gakkai Zasshi 48: 375-378, 2010 (In Japanese).

28. Iwamura T, Shibata N, Haraguchi Y, Hisashi Y, Nishikawa T, Yamada H, Hayashi T and Toyoda K: Synchronous double cancer of the stomach and rectum with situs inversus totalis and polysplenia syndrome. J Clin Gastroenterol 33: 148-153, 2001.

29. Dulganov KP and Nelip VE: Synchronous early cancer of the esophagus and larynx in a patient with complete situs viscerum inversus. Vopr Onkol 36: 1125-1126, 1990 (In Russian).

30. Guerra Rosseau R, Daumy Amat O, De Armas Haramboure L and Andial A: Case of multiple cancer and situs inversus. Arch Cuba Cancerol 11: 61-65, 1952 (In Undetermined Language).

31. Kim YI, Tada I, Kuwabara A and Kobayashi M: Double cancer of the liver and stomach with situs inversus totalis-a case report. Jpn J Surg 19: 756-759, 1989.
32. Vijayakumar V and Brandt T: Prolonged survival with isolated levocardia and situs inversus. Clev Clin J Med 58: 243-247, 1991.

33. Pathak P, Zilberman V, Avezbakiyev B and Gotlieb V: Hairy cell leukemia in a patient with situs inversus totalis: An extremely rare combination. Future Oncol 9: 753-756, 2013.

34. Yun S, Vincelette ND, Phan T and Anwer F: Spontaneous tumour lysis syndrome associated with contrast dye iohexol use in mantle cell lymphoma. BMJ Case Rep 2014: pii: bcr2014204113, 2014

35. Trautner M, Szyszko T, Gnanasegaran G and Nunan T: Interesting image. Situs inversus totalis in newly diagnosed lymphoma: Additional value of hybrid imaging. Clin Nucl Med 35: 26-28, 2010.

36. Patel RV, Mehta MH, Bhoot NH, Gondalia JS and Ghodadra JK: Ileocecal lymphoma presenting as an epigastric mass. Indian Pediatr 29: 519-521, 1992. 